\title{
OS DILEMAS DA ESCOLA REPUBLICANA
}

\author{
Juliana Regina Basilio*
}

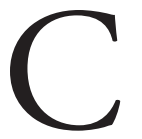

onsiderado um marco na construção da teoria da dominação cultural a que o primeiro autor dedicaria a maior parte de sua vida, o livro $O s$ Herdeiros, de Pierre Bourdieu e Jean-Claude Passeron, muito contribuiu para fazer avançar a nossa compreensão sobre o lugar social da escola contemporânea. É ali que aparece pela primeira vez o conceito de capital cultural, apoiado por resultados de uma pesquisa empírica de fôlego. Não é, portanto, surpreendente que seu cinquentenário tenha dado ocasião para um retorno reflexivo sobre essa obra, marcado por seminários e várias publicações. O livro do professor Michel Éliard, Bourdieu ou l'Héritage républicain récusé (Bourdieu ou a recusa do legado republicano), é uma das muitas iniciativas desse tipo que tiveram lugar na França entre 2013 e 2014.

Michel Éliard é professor emérito da Universidade de Toulouse II Mirail, França, onde trabalhou desde 1967, depois de colaborar em alguns dos trabalhos desenvolvidos no Centre de Sociologie Européenne. Participou, em particular, da pesquisa que deu origem a obra Os Herdeiros, tendo também coautorado o livro Les étudiants et leurs études (Paris: La Haye, Mouton) publicado no mesmo ano. Éliard fala, portanto, com a autoridade de quem se diz conhecedor dos bastidores e o tom confessional, ainda que um tanto ressentido, com que se rende à tarefa de discutir o livro revela isso:

Je n'ai jamais raconté mon rôle dans cette histoire mais le cinquantenaire de ce best-seller est l'occasion de donner ma part de vérité sur l'origine d'un livre qui continue à défrayer la chronique et qui, en 2014, le fera peut-être encore. (Éliard, 2014, p.38)

É nomeando-se como defensor da escola republicana que Éliard analisa a obra de Bourdieu. Seu argumento pode ser resumido da seguinte maneira: (i) a escola pública francesa é um legado precioso da III República, resultado de uma

\footnotetext{
* Resenha do livro de Éliard, Michel. Bourdieu ou l'Héritage républicain récusé. Toulouse, France: Presses Universitaires du Mirail, 2014. [Collection Sociologiques]

** Doutoranda Faculdade de Educação, Universidade Estadual de Campinas, Campinas, SP., Brasil. Bolsista Capes e Fapesp. E-mail de contato: pepebasilio@gmail.com.
} 
longa luta que se inicia com a Revolução de 1789; (ii) negar seu valor positivo implicaria na destruição da própria escola pública; (iii) a sociologia da escola, proposta por Bourdieu, faz uma crítica a essa escola, negando seu valor positivo, e, por isso, colabora para sua destruição.

Temos aqui, portanto, a afirmação da escola pública como um bem para a sociedade. Uma ideia, aliás, compartilhada por muitos outros autores. O que é mais surpreendente, e talvez menos sustentável, é a ideia de que críticas aos limites do modelo de escola republicana, forjado no século XIX, colocariam a perder esse legado.

Essa é uma chave importante para entender o livro que, desde o título, está organizado para tratar a obra de Bourdieu como um caso de recusa do legado republicano. A própria iconografia é mobilizada para estruturar esse argumento. Assim, a capa do livro traz a fotografia do autor e a de Condorcet, lado a lado. Se Condorcet aparece imponente, com um olhar focado e pose feita, Bourdieu aparece sentado, meio curvado, com os cotovelos sobre as pernas, as mãos juntas encostadas entre o queixo e a boca, a testa franzida e um olhar perdido, sem pose. Nada ao acaso, Condorcet (1743-1794), matemático e filósofo iluminista, que construiu um projeto de reforma da instrução pública na França em 1792, representa, ali, perante um Bourdieu que parece mergulhado em incertezas, o orgulho e a convicção da positividade do legado republicano.

Bourdieu ou l'héritage républicain récusé é composto de nove capítulos mais introdução e conclusão. Penso que podemos lê-lo em duas partes: uma primeira, composta pelos capítulos que apresentam, cada um a seu turno, os livros em que Bourdieu desenvolve progressivamente sua análise da escola: Les Héritiers (cap. II), La Réproduction (cap. III), La Noblesse d'État (cap. IV), e o livro póstumo Sur l'État (cap. VI). A segunda parte dedica-se de maneira mais minuciosa aos processos que levaram à construção da escola republicana francesa no decorrer da terceira república, às características específicas dessa instituição e, por fim, à discussão sobre a importância, para a classe trabalhadora, do controle do estado sobre o valor do diploma (caps. VIII e IX).

Ao longo do texto, Éliard confronta a crítica bourdieusiana aos limites da escola republicana com a defesa do seu legado positivo. A partir do capítulo VIII, no entanto, o argumento fica mais claro e compreendemos que, segundo Éliard, atribuir a perpetuação das desigualdades sociais à escola republicana, como faz a obra de Bourdieu, significa contribuir para sua decadência (p.12).

Além dessa crítica de fundo, que equivale a dizer que Bourdieu não compreendeu a natureza dessa instituiçáo preciosa e particular, o autor procura mostrar que as conclusóes de Os Herdeiros não são devidamente amparadas pelos resultados de pesquisa apresentados no livro. Os questionários utilizados não seriam suficientes para provar as hipóteses de Bourdieu e Passeron (p.39). Aplicados 
apenas aos estudantes dos cursos de filosofia e sociologia, não poderiam sustentar a generalização dos resultados para outras áreas. Além disso, haveria falhas na análise histórica, já que os autores teriam negligenciado a importância da conquista representada pela expansão do ensino gratuito e laico para a luta de classes.

Éliard desenvolve nesse ponto uma visão alternativa sobre a relação das classes trabalhadoras com a escola. Ele argumenta que a escola republicana é diretamente responsável pelo acesso das camadas menos privilegiadas à escola, ao garantir a autonomia desses grupos com relação à escola privada. Como consequência, a escola republicana ofereceria a importante contribuição de permitir a todos a apropriação das "conquistas culturais da humanidade", isto é, da "cultura burguesa” (p.48).

Ele procura mostrar que à medida que foi tendo acesso à escola - por meio principalmente das fileiras profissionais -, a classe trabalhadora movimentou-se para que sua qualificação fosse reconhecida e para que os salários fossem atrelados a ela. A luta social que garantiu essas conquistas seria, para o autor, um atestado da capacidade emancipadora da classe trabalhadora. As reformas das décadas de 1960 e 1970, que instauraram o colégio único, aboliram as fileiras técnicas no nível de ensino que corresponde ao que se considera no Brasil como a segunda parte do ensino fundamental em nome da igualdade de chances. Residiria aí, para Éliard, o grande problema enfrentado pela escola republicana no final do século XX, já que a criação da escola única teria destituído os trabalhadores de armas muito eficazes para enfrentar a dominação capitalista.

Seria por não reconhecer a importância dessa conquista que Bourdieu e Passeron puderam tomar a origem social como variável explicativa para as desigualdades de desempenho escolar, abrindo caminho, segundo Éliard, não só para as reformas das décadas de 1960 e 1970, mas para os experimentos mais recentes em políticas de discriminação positiva que, segundo ele, além de não terem contribuído para a diminuição das desigualdades, teriam abalado o próprio edifício da igualdade de direitos.

O argumento de Éliard revela com bastante precisão a posição ambígua em que se encontram os analistas da escola republicana pelo menos desde que autores como Bourdieu revelaram sua contribuição à reprodução social: como enfrentar os seus limites sem abdicar dos seus benefícios? Acredito que esse livro apresenta esse problema embora não contribua para avançar na sua solução.

\section{Referências}

BOURDIEU, P.; PASSERON, J. C.; ÉLIARD, M. Les étudiants et leurs études. Paris: La Haye, Mouton, 1964. 
BOURDIEU, P.; PASSERON, J.-C. Les Héritiers: les étudiants et la culture. Paris: Les Éditions de Minuit, 1964. [Collection le sens commun].

. La Reproduction: éléments pour une théorie du système d'enseignement. Paris: Les Éditions de Minuit, 1970. [Collection Le sens commun].

BOURDIEU, P. La Noblesse d'État: grandes écoles et esprit de corps. Paris: Les Éditions de Minuit, 1989.

. Sur L'État. Cours au Collège de France, 1989-1992. Paris: Seuil, 2012. [Collection Raisons d'agir].

ÉLIARD, M. Bourdieu ou l'Héritage républicain récusé. Toulouse, France: Presses Universitaires du Mirail, 2014. [Collection Sociologiques].

Recebido em 24 de setembro de 2014.

Aprovado em 09 de março de 2015. 